\title{
COMPARTIMENTAÇÃO GEOAMBIENTAL DO PLANALTO DA IBIAPABA: SUBSÍDIOS AO MANEJO DOS RECURSOS NATURAIS NOS MUNICÍPIOS DE TIANGUÁ E UBAJARA - CEARÁ
}

\author{
Francisco Leandro de Almeida Santos ${ }^{(a)}$, Flávio Rodrigues do Nascimento ${ }^{(b)}$
}

(a) Universidade Estadual do Ceará. leogeofisico@gmail.com

(b) Universidade Federal do Ceará. flaviogeo@ @ol.com.br.

Eixo: GEOTECNOLOGIAS E MODELAGEM ESPACIAL EM GEOGRAFIA FÍSICA

\section{Resumo}

Os municípios de Tianguá e Ubajara estão localizados no setor setentrional do Planalto da Ibiapaba, noroeste do Ceará, se destacando como objeto empírico da pesquisa pela diversificação das tipologias de uso e ocupação da terra que justificam a instalação de problemas ambientais sobre o meio físico-biótico. Assim, a discussão se pauta nos preceitos da análise integrada da paisagem como base de método para uma proposta de ordenamento territorial ao desenvolvimento das atividades produtivas em compatibilidade com a capacidade de suporte dos sistemas ambientais. Os procedimentos operacionais foram divididos em quatro etapas: 1) Revisão da literatura; 2) Interpretação de imagens orbitais; 3) Elaboração do mapeamento temático; 4) Trabalho de campo. Após as discussões, os resultados expõem a sinopse da compartimentação geoambiental definindo estratégias de manejo adequado dos recursos naturais com intervenções que visam à sustentabilidade ecológica e econômica.

Palavras chave: Sistemas ambientais, tipologias de uso e ocupação, ordenamento territorial.

\section{Introdução}

A análise integrada da paisagem desempenha importante um papel no campo de investigação da ciência geográfica, contribuindo no âmbito da discussão que permeia a questão ambiental. Essa abordagem conduz ao entendimento holístico da relação sociedade-natureza, sobretudo, no contexto que emerge uma progressiva expansão dos processos produtivos, perante a necessidade de repensar os paradigmas do capitalismo contemporâneo na busca pelo uso sustentável dos recursos naturais.

Nesse cenário, a ciência geográfica assume um novo posicionamento frente aos desafios voltados para a interpretação das escalas de atuação da sociedade na degradação dos recursos naturais, vislumbrando a elaboração de metodologias guiadas pela abordagem sistêmica para uma contribuição efetiva no âmbito de diretrizes ao processo planejamento ambiental.

Não obstante, o Ceará vem passando a partir da década de 1990 por um incremento significativo na sua economia, sobretudo, por conta dos investimentos direcionados aos grandes equipamentos turísticos e viabilização do vetor agroindustrial na cadeia produtiva do território. Desse modo, o modelo de desenvolvimento econômico regional vem conduzindo a exploração dos recursos naturais para além da capacidade de suporte dos sistemas ambientais, implicando na degradação da biodiversidade primária.

Desta forma, as potencialidades de recursos naturais no Planalto da Ibiapaba propiciaram formas diferenciadas de uso e ocupação da terra no cenário regional do noroeste cearense, inserindo a área no processo de reprodução ampliada do capital. Assim, nos municípios de Tianguá e Ubajara os problemas ambientais emergiram pela 


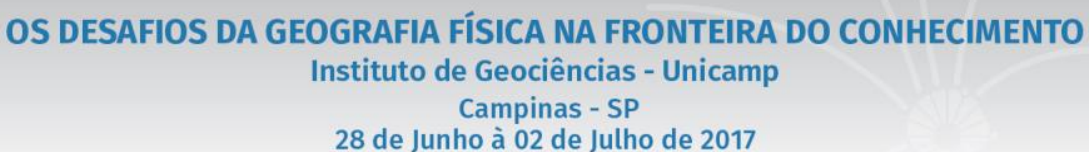

projeção de agentes econômicos que promoveram o desenvolvimento das atividades produtivas, se destacando os setores de turismo, lazer, serviços e do agronegócio.

A pesquisa possui relevância para sociedade por traçar diretrizes ao ordenamento territorial a partir da análise geoambiental integrada como base de método das estratégias que contemplam o uso disciplinado dos recursos naturais. Deste modo, a presente pesquisa estabelece a compartimentação geoambiental do objeto empírico como requisito fundamental para possibilitar uma articulação dos critérios de base geográfica com a tomada de decisões públicas no contexto do ordenamento territorial.

A discussão da base de método da pesquisa se pauta na importância da matriz geossistêmica para os estudos integrados em Geografia Física com foco na hierarquização das unidades de paisagem Para Bertrand (op. cit.), o geossistema que corresponde ao quarto nível de hierarquização, pode ser considerado como o mais importante nos estudos geográficos por apresentar de forma consistente uma tipologia espaço-temporal compatível com a escala de atuação das atividades humanas. Em suma, os geossistemas resultam da combinação entre o potencial ecológico e a exploração biológica, integrados por vários elementos que mantêm relações mutuas e interdependentes no que tange aos fluxos de matéria e energia.

Souza (2000) faz adaptações na metodologia de Bertrand (op. cit) sobre aspectos de aplicação da concepção geossistêmica às características naturais do Nordeste brasileiro. Nessa abordagem, o componente geomorfológico é utilizado como guia para delimitação das unidades de paisagem, dada as suas condições de síntese dos processos ambientais. Os limites do relevo e as feições do modelado são mais facilmente identificados e passíveis de uma compartimentação mais rigorosa e precisa. Além disso, deve-se reconhecer que a compartimentação geomorfológica deriva da herança geoambiental do Quaternário. Como tal, cada compartimento tende a ter padrões próprios de drenagem superficial, arranjos típicos de solos e características singulares quanto à estruturação dos aspectos fitogeográficos.

Desta feita, as particularidades do quadro geoambiental tendem a repercutir nas tipologias de uso e ocupação da terra pela diversificação dos recursos naturais, ensejando condições de potencialidades e limitações para o desenvolvimento das atividades socioeconômicas. Assim, o objetivo geral da pesquisa se pauta em estabelecer subsídios ao manejo adequado dos recursos naturais para os municípios de Tianguá e Ubajara via desdobramento dos estudos ambientais integrados na definição de diretrizes que promovam o desenvolvimento econômico em compatibilidade com a capacidade de suporte dos sistemas ambientais.

\section{Materiais e Métodos}

Na elaboração do mapa planialtimétrico, foi utilizada uma imagem SRTM (SHUTTLE RADAR TOPOGRAPHY MISSION), com resolução espacial de 90 metros, folha SA-24-Y-C, na escala de 1:250.000, disponibilizada pela EMBRAPA (EMPRESA BRASILEIRA DE PESQUISA AGROPECUÁRIA). O software Global Mapper, versão 11 possibilitou à extração dos padrões de drenagem e a elaboração do perfil topográfico. $\mathrm{O}$ critério 
OS DESAFIOS DA GEOGRAFIA FÍSICA NA FRONTEIRA DO CONHECIMENTO

Instituto de Geociências - Unicamp

Campinas - SP

28 de Junho à 02 de Julho de 2017

geomorfológico subsidiou a compartimentação geambiental através da elaboração de um perfil topográfico no

Programa Global Mapper 11. A utilização da Imagem SRTM possibilitou a extração das curvas de nível em isoípsas de $100 \mathrm{~m}$ com modelo digital de terreno em base tridimensional.

Após a rigorosa delimitação dos arranjos espaciais dos sistemas ambientais, com apoio da geomorfologia e de seus padrões de drenagem, o mapeamento foi executado no SIG QUANTUM GIS 1.8, cuja composição da legenda corresponde à integração de variáveis oriundas do estudos setorizados da natureza no contexto de suas interconexões para formar padrões uniformes de paisagem.

As tipologias de uso e ocupação da terra foram identificadas através da análise de imagens orbitais do satélite LANDSAT 8 com resolução espacial de $15 \mathrm{~m}$. A imagem foi fusionada no software SPRING 5.2.6 com base no método IHS para visualização dos processos produtivos. Após o tratamento da imagem, a vetorização e composição da legenda foram realizadas no SIG QUANTUM GIS 1.8, gerando o mapeamento na escala de 1/220.000. O Trabalho de campo foi imprescindível para o reconhecimento da realidade terrestre. O GPS GARMIN E TEX 10, com apoio da Carta Imagem do satélite LANDSAT 8 possibilitaram a tabulação dos dados no gabinete para guiar a correção do mapeamento temático.

\section{Resultados e Discussão}

\subsection{Contexto Biofísico do Planalto da Ibiapaba}

Os municípios de Tianguá e Ubajara localizam-se na porção noroeste do Ceará integrando o setor setentrional do Planalto da Ibiapaba. Esse importante compartimento de relevo representa a borda oriental da Bacia sedimentar do Parnaíba através de um escarpamento abrupto e festonado pelo trabalho da esrosão diferencial no contato com a depressão sertaneja e um caimento topográfico suave para oeste em direção ao estado do Piauí, configurando-se numa morfologia de cuesta.

Ab’ Saber (1969), expõe a influência dos processos morfoclimáticos do Quaternário sobre a evolução dos compartimentos de relevo em singularidade com a distribuição dos domínios fitogeográficos do Brasil. Durante a fase tropical úmida, a distribuição areolar da Mata Atlântica assumiu contornos expressivos nas paisagens intertropicais, denunciando uma fase extensiva de dissecação das vertentes e espessamento dos mantos de intemperismo com o consequente desenvolvimento dos solos. A fase de semiaridez agressiva contribuiu para a atuação da morfogênese mecânica sobre o relevo, esboçando a configuração de amplas superficies de pedimentação concomitante à retração das florestas tropicais para os refúgios ecológicos, à medida que as caatingas ralas expandiam-se pelas depressões intermontanas favorecendo a remoção dos solos desprotegidos face aos efeitos das chuvas torrenciais.

Neste víeis, o mecanismo evolutivo do Planalto da Ibiapaba expõe as influências das mudanças ambientais que ocorreram ao longo da história geoecológica do Quaternário. Esquematicamente, ora pelo predomínio da morfogênese química através da superimposição da rede hidrográfica pela dissecação e abertura prévia dos vales, 


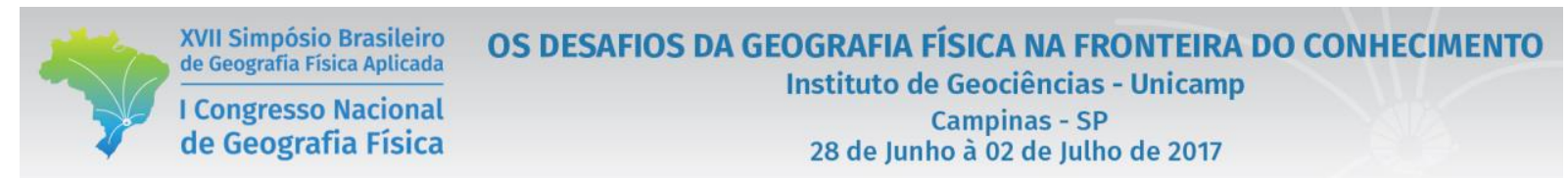

ora pela atuação da morfogênese mecânica através da ação simultânea do recuo paralelo da escarpa com a exumação do embasamento cristalino na área da depressão periférica. A disposição do relevo frente ao deslocamento dos ventos úmidos provenientes do oceano Atlântico favorece a ocorrência de chuvas orográficas nas vertentes e nos níveis de cimeira do planalto, potencializando a existência de um enclave de mata úmida em meio aos sertões semiáridos circunjacentes.

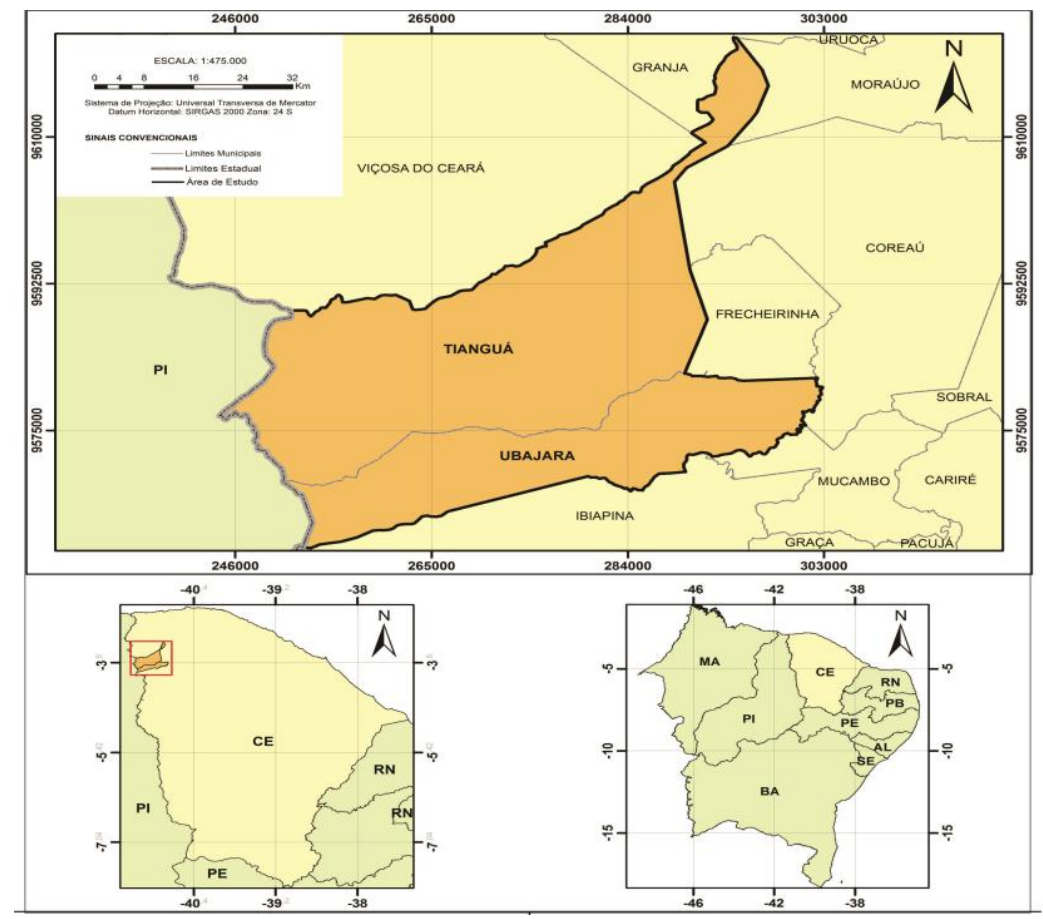

Mapa1: Localização da área de estudo. Fonte: IPECE (2013).

O arranjo fitogeográfico testemunha as variações climáticas do Quaternário frente à existência de refúgios ecológicos da Mata Atlântica em meio ao ambiente semiárido. Nas condições atuais, a mata úmida ocupa a cimeira do planalto a partir da retração fitogeográfica para os setores onde a dinâmica ambiental ainda se mantém próxima das que deram origem a esse contexto geobotânico.Tais condições esboçam a configuração de um verdadeiro brejo de altitude no contexto das caatingas semiáridas.

Os Latossolos Vermelho-Amarelos ocorrem principalmente no platô úmido em decorrência da decomposição do capeamento arenítico da Formação Serra Grande. O estágio avançado de pedogênização é desenhado como resposta à influência das condições climáticas úmidas na consolidação de sugestivos "brejos de altitude" com características que exprimem uma tipicidade geoecológica peculiar ao contexto das paisagens de exceção do Nordeste brasileiro.

$\mathrm{Na}$ área do reverso a semiaridez prepondera em razão da atenuação das chuvas orográficas sobre a área de disposição do relevo justificando a dispersão fitogeográfica do carrasco em associação com os Neossolos 


\section{OS DESAFIOS DA GEOGRAFIA FÍSICA NA FRONTEIRA DO CONHECIMENTO \\ Instituto de Geociências - Unicamp \\ Campinas - SP \\ 28 de Junho à 02 de Julho de 2017}

Quartzarênicos. A drenagem possui orientação consequente em corcodância com o mergulho estratigráfico das rochas sedimentares até as rupturas de declive com a depressão monoclinal.

Desta forma, o mapa planialtimétrico traduz em três dimensões o jogo de influências das variáveis mofoestruturais e morfoesculturais no condicionamento da feição cuestiforme no recorte municipal de Tianguá e Ubajara. Ademais, o esquema tridimensional representa a ruptura topográfica entre depressão periférica e a frente escarpada da cuesta através do perfil dos níveis de erosão em isoípsas de $100 \mathrm{~m}$.

O modelo salienta a disposição do relevo numa altitude acima de $700 \mathrm{~m}$, configurando um importante dispersor de drenagem da bacia hidrográfica do rio Coreaú, a partir da ressurgência de nascentes que assumem orientação obsequente, propiciando o ataque da erosão remontante no contexto morfogenético da vertente oriental do planalto. Nesse aspecto, o traçado das isoípsas sobre a escarpa da cuesta traduz a dissecação da drenagem obsequente em oposição ao controle da morfoestrutura, demandando coletores por captura fluvial até a área da depressão sertaneja, visto a condição dos rios em impor a abertura dos vales no sentido inverso ao mergulho estratigráfico das camadas sedimentares.

O arranjo espacial da superfície sertaneja resulta do recuo do Planalto da Ibiapaba para oeste como reflexo da condição de semiaridez quaternária. A coalescência das rampas de pedimentação possibilitou a existência de inselbergs e cristas residuais como resultado da morfogênese mecânica, onde se sobressaíram setores de maior resistência litológica frente ao aplainamento progressivo do relevo regional. Há a dispersão fitogeográfica do Bioma Caatinga que recobrem solos de tênue evolução pedogenética se comparados com os Latossolos Vermelho-Amarelos do platô úmido do planalto.

Em contraponto, o controle da morfoestrutura no reverso impõe um comportamento morfoescultural no ajustamento do caimento topográfico. Há o mergulho gradativo das rochas para o eixo da sinéclise, condicionando à adaptação da drenagem consequente que assume padrão paralelo na elaboração de vales pedimentados até confluir para o rio Parnaíba. Além disso, o perfil topográfico certifica a presença da depressão monoclinal nos municípios de Tianguá e Ubajara com níveis altimétricos de $200 \mathrm{~m}$, em semelhança à depressão sertaneja.Trata-se de uma superfície de aplainamento mapeada na escala de trabalho cujo detalhamento $1 \backslash 50.000$ permite a identificação das feições morfoesculturais com maior rigor no tratamento da expressão espacial que compõe a organização do arranjo geomorfológico. 


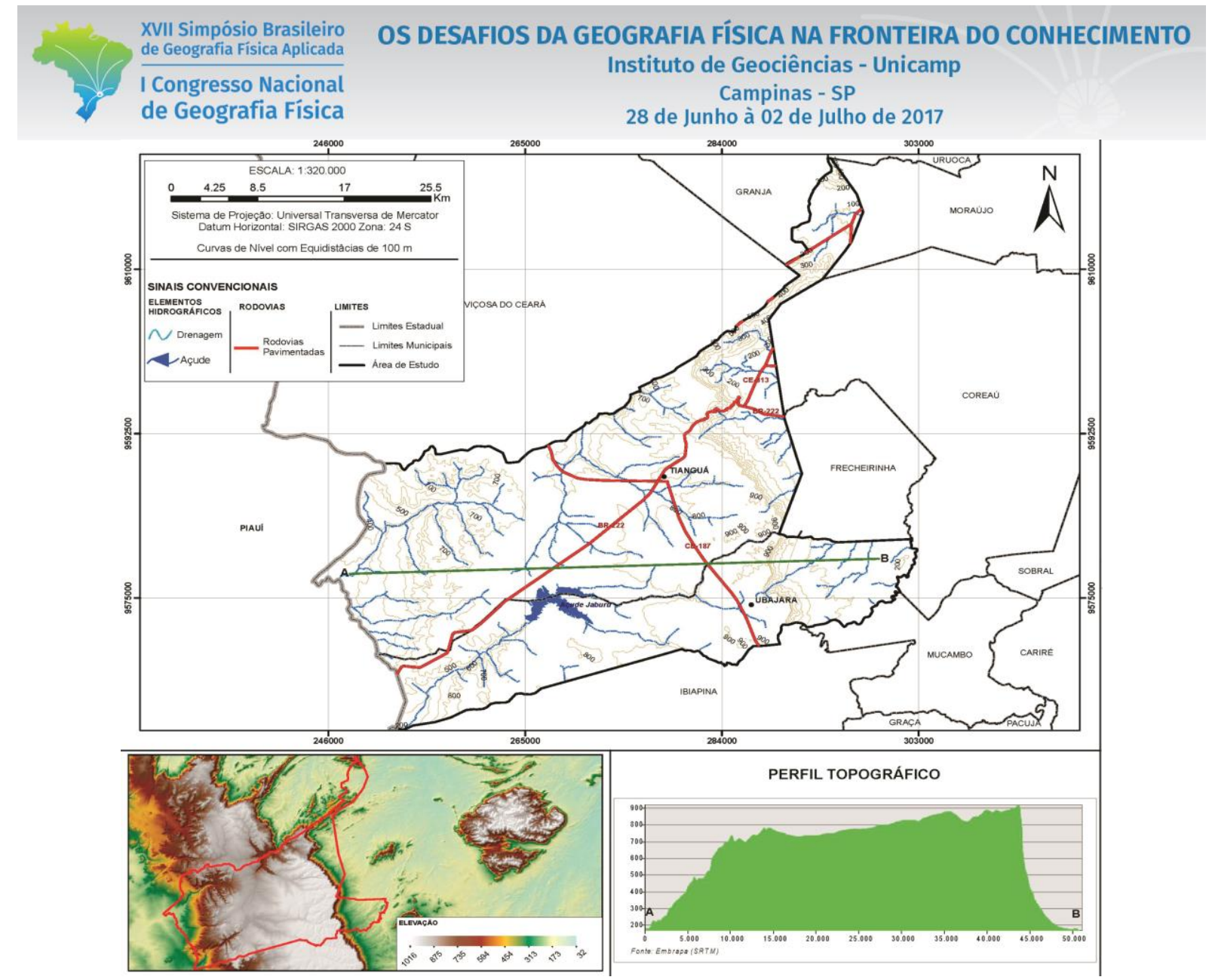

Mapa 2: Modelo planialtimétrico com perfil topográfico dos municípios de Tianguá e Ubajara. Fonte: EMBRAPA (2014).

\subsection{Condições de uso e ocupação da terra}

A configuração das tipologias de uso e ocupação nos municípios de Tianguá e Ubajara resulta da ação conjugada dos diferentes agentes na produção do espaço geográfico, via reprodução das atividades econômicas sobre o substrato biofísico dos sistemas ambientais por múltiplos interesses e complexas relações de apropriação dos recursos naturais disponíveis. Sob esse aspecto, as tipologias de uso e ocupação assumem particularidades, promovendo a instalação dos problemas ambientais de acordo com a pressão que cada atividade econômica exerce sobre a dinâmica do meio natural.

As tipologias de uso e ocupação da terra estão relacionadas aos modelos de exploração dos recursos naturais em virtude do seu valor econômico-social e das atividades exercidas em determinadas áreas como agricultura, desenvolvimento urbano, turístico e industrial, além da implantação da estrutura de base sofisticada. Esses fluxos, em geral, são operados entre o local e o global pela atuação dos agentes produtores do espaço, cujos, efeitos se manifestam nas mudanças ambientais em diferentes escalas (NASCIMENTO, 2006).

Desta forma, as tipologias expostas no mapa abaixo são: 1) Área Urbana; 2) Área de Pousio; 3) Áreas Legalmente Protegidas; 4) Agricultura Tecnificada; 5) Agricultura de Sequeiro Associada á Pecuária Extensiva; 6) Policultura Associada à Pecuária Semi-iintensiva; 


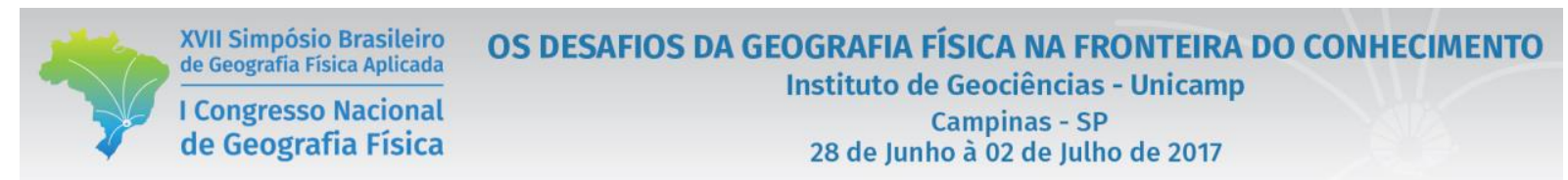

As áreas urbanas estão alocadas sobre o platô úmido do Planalto da Ibiapaba, dispostas num sentido norte-sul conforme a zona de influência do brejo de altitude. Não obstante, as relações de interdependência entre o potencial ecológico e a exploração biológica tiveram suas variáveis alteradas, à medida que a vegetação foi suprimida para ceder lugar às construções residenciais, a impermeabilização de ruas e avenidas e a edificação de prédios comerciais. Vale ressaltar, que os problemas ambientais se remetem às condições de infraestrutura domiciliar, principalmente no que tange aos setores desprovidos de esgotamento sanitário, coleta de lixo e sistema de drenagem urbana.Há o empobrecimento da biodiversidade primária, além da pressão sobre os recursos hídricos nas Áreas de Preservação Permanente pelo crescente adensamento demográfico no perímetro das sedes urbanas.

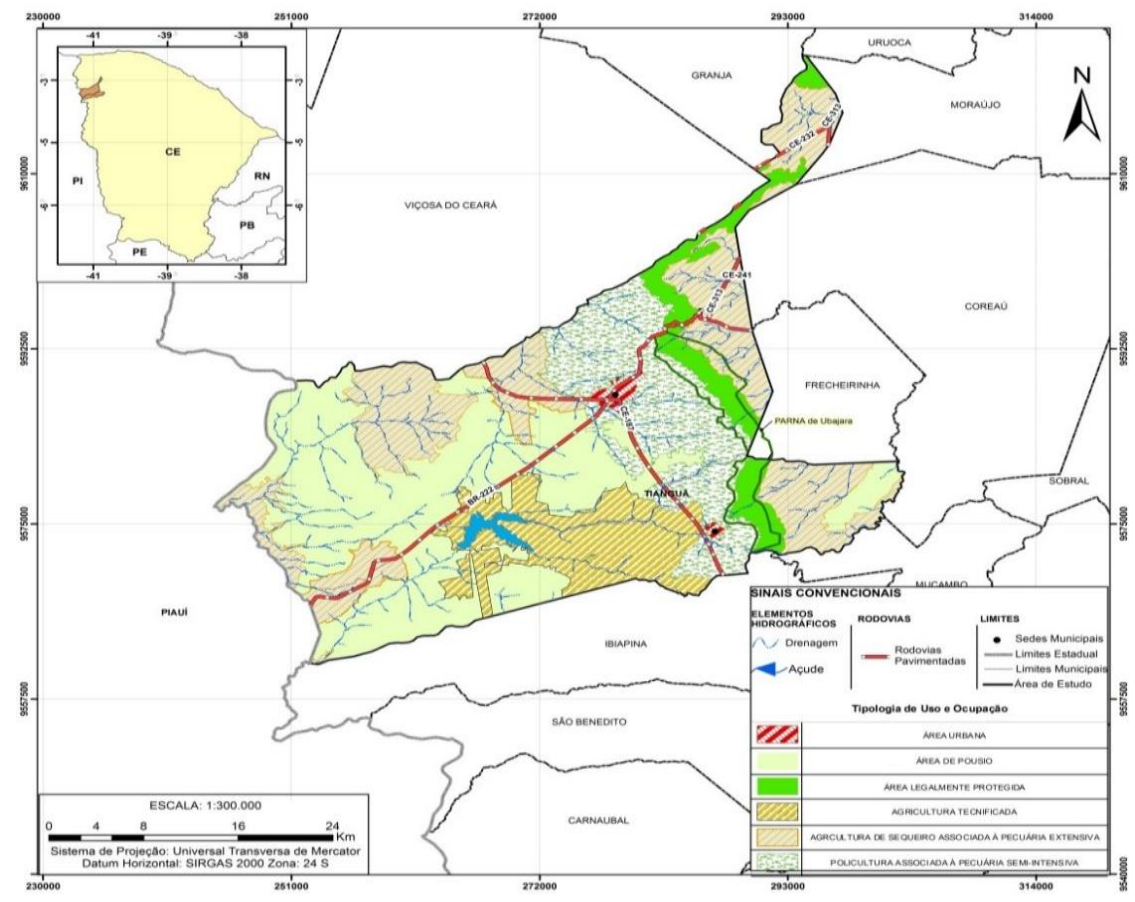

Mapa 3: Tipologias de Uso e Ocupação da Terra. Fonte: EMBRAPA (2014).

As áreas em pousio são consideradas setores de reserva para especulação fundiária e imobiliária.Além disso, compõem as áreas cuja capacidade produtiva dos recursos naturais foi exaurida pela intensa utilização agrícola condicionando a ruptura do equilibrio dinâmico dos sistemas ambientais.

As áreas legalmente protegidas se remetem à regulamentação do Novo Código Florestal em vigor desde 2012. Correspondem as vertentes escarpadas do Planalto da Ibiapaba e cristas residuais na área da depressão sertaneja, no qual a declividade das encostas se constitui no principal fator limitante à ocupação humana. Compreendem setores de Uso Restrito, além das Áreas de Preservação Permanentes definidas pela legislação ambiental pertinente em regime de proteção compulsória, onde pontualmente se pratica o ecoturismo em vias sustentáveis. 


\section{OS DESAFIOS DA GEOGRAFIA FÍSICA NA FRONTEIRA DO CONHECIMENTO \\ Instituto de Geociências - Unicamp \\ Campinas - SP \\ 28 de Junho à 02 de Julho de 2017}

$\mathrm{Na}$ vertente úmida, os Argissolos Vermelho-Amarelos possuem condições de média a alta fertilidade natural. Todavia, a legislação ambiental estabelece aspectos limitativos ao manejo dos recursos naturais.Trata-se de um ambiente cuja declividade condiciona a ocorrência de movimentos gravitacionais em condições ecodinâmicas de forte instabilidade. O Parque Nacional de Ubajara apresenta-se como uma área legalmente protegida em meio ao arranjo do setor produtivo do Planalto da Ibiapaba, principal vetor de degradação ambiental da área de entorno á Unidade de Conservação. Corresponde a uma Unidade de Proteção integral estabelecido pelo SNUC (2000), instituído legalmente pelo poder público com objetivos de preservar a natureza sendo permitido apenas o uso indireto dos recursos naturais em regime especial de administração, na qual se aplicam garantias adequadas à proteção.

Nessa perspectiva, o ecoturismo se tornou uma alternativa compatível com a capacidade de suporte dos sistemas ambientais contribuindo para conservação dos recursos naturais disponíveis.Dentre as atividades cabe menção, a visita ao horto florestal através do percurso de trilhas ecológicas com vista para cascatas obsequentes na área da vertente úmida, além do teleférico que dá acesso à gruta de Ubajara. Conforme ilustra a figura abaixo:

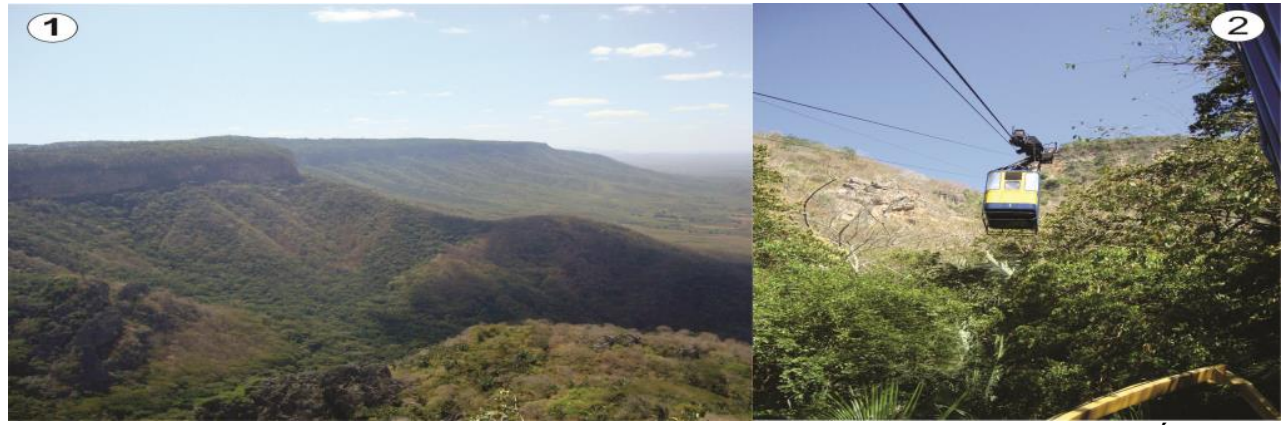

Foto 1: Contato da Vertente do Planalto da Ibiapaba com a Depressão Periférica Circunjacente na Área do Parque Nacional de Ubajara. Foto 2: Teleférico com Acesso a Gruta de Ubajara. Fonte: autores (2015).

$\mathrm{Na}$ área da depressão periférica se pratica a agricultura de sequeiro associada á pecuária extensiva.Há pequenos investimentos por parte do Estado em infraestrutura para inserção da área na cadeia produtiva do agronegócio. Prevalecem práticas agrícolas de baixo nível tecnológico com ciclos periódicos geralmente vinculados a quadra chuvosa. Nessas condições, o setor possui baixa produtividade atendendo a demanda de subsistência das populações locais. Em suma, essas áreas são ocupadas pelo cultivo rudimentar do milho, feijão e mandioca com pouco investimento de capital.

Não obstante, a expansão da agricultura tecnificada nos municípios de Tianguá e Ubajara se remete a incorporação da irrigação como mecanismo que atraiu maciços investimentos de grandes empreendimentos rurais. A disponibilidade hídrica do Açude Jaburu e os avanços no campo da tecnologia agrícola propiciaram o aumento da produtividade nos setores de fruticultura e horticultura, potencializando a pressão ambiental sobre a área do reverso seco e parte do platô úmido. Assim, o incremento de agrotóxicos em torno dos rios e reservatórios 


\section{OS DESAFIOS DA GEOGRAFIA FÍSICA NA FRONTEIRA DO CONHECIMENTO \\ Instituto de Geociências - Unicamp \\ Campinas - SP \\ 28 de Junho à 02 de Julho de 2017}

artificiais comprometem a qualidade dos recursos hídricos, exibindo riscos ao abastecimento de água para população local.

Além disso, a agricultura associada à pecuária semi-intensiva na área do platô úmido promoveu o desmatamento da mata plúvio-nebular com implicações sobre a biodiversidade conduzindo a ruptura do equilíbrio dinâmico do ambiente, conforme ilustra as figuras abaixo:
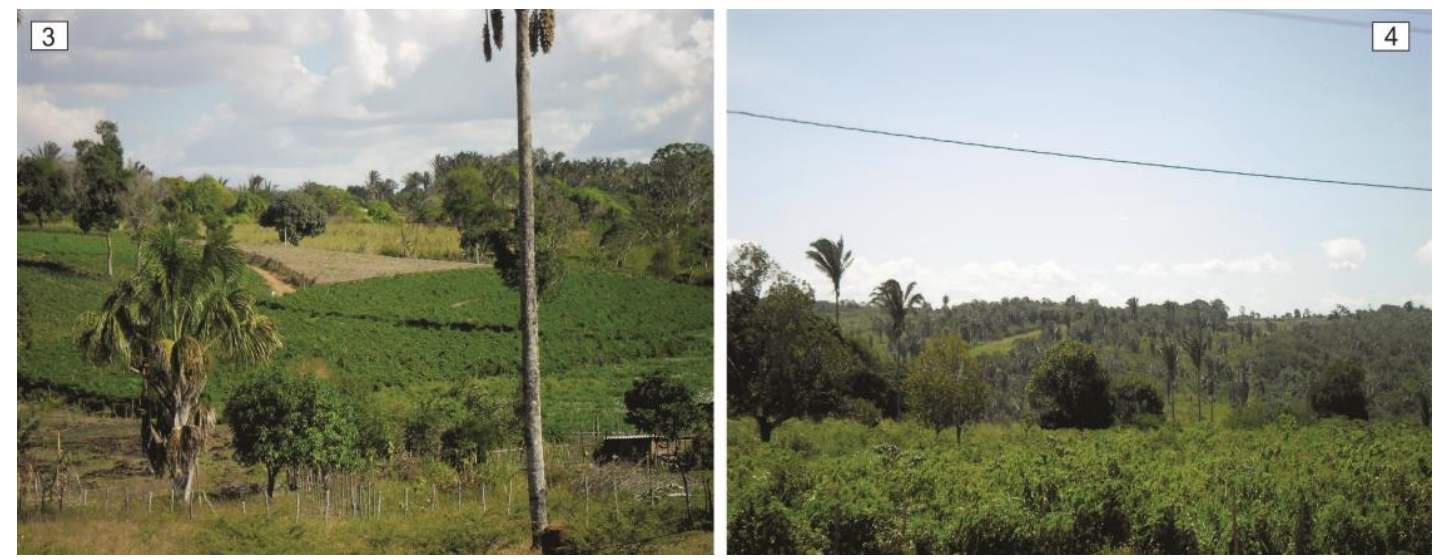

Foto 3: Produção de Maracujá no município de Ubajara. Foto 4: Predomínio do babaçu como indicativo de desmatamento no município de Tianguá. Fonte: Autores (2014).

A presença expressiva do babaçu testemunha a distribuição original da mata plúvio-nebular e ao mesmo tempo presume a existência de um estagio avançado de degradação ambiental. Não obstante, o desmatamento generalizado do conjunto vegetacional primitivo faz com que essas espécies passem a prevalecer na paisagem secundária, visto a sua maior resistência nos processos de competição biológica. A disponibilidade hídrica do enclave úmido da Ibiapaba aliada às características naturais dos Latossolos Vermelho-Amarelos favorecem a introdução de policulturas variadas nas diferentes propriedades rurais. No entanto, os produtores recorrem ao emprego de agrotóxicos, fertilizantes químicos e corretivos de acidez, no intuito de adequar a atividade agrícola às condições de baixa fertilidade natural dos solos.

Os setores de fruticultura agregam o uso de agrotóxicos para conter o avanço de pragas sobre a produção. Tais ações comprometem a qualidade ambiental, à medida que contaminam os solos, bem como os recursos hídricos superficiais e subterrâneos. Além disso, a devastação generalizada da mata pluvio-nebular coloca em evidência a necessidade de conservação da biodiversidade primária através do controle das fronteiras agrícolas com incentivo à introdução de sistemas agroecológicos.

Nesse aspecto, a introdução do agronegócio como base econômica dos municípios de Tianguá e Ubajara promoveram problemas ambientais em diferentes magnitudes, colocando em evidencia a necessidade de um modelo adequado de ordenamento territorial pautado no desenvolvimento das atividades produtivas em compatibilidade com a capacidade de suporte dos sistemas ambientais. 


\subsection{Compartimentação Geoambiental}

A compartimentação geoambiental representa um instrumento indispensável para execução dos mecanismos ligados ao processo de ordenamento do território, contemplando uma etapa considerada ponto chave para as diretrizes que integram o turismo sustentável.

Souza (2000) à luz do método geossistêmico de Bertrand (1972), faz adaptações sobre a definição das unidades de paisagem. Nessa abordagem, o critério geomorfológico é utilizado como guia para mensurar a diversidade interna dos geossistemas no contexto do semiárido brasileiro. Desta forma, foi imprescindível a delimitação dos geofácies como parte integrante do mesmo sistema de relações entre o potencial ecológico e a exploração biológica Tais unidades foram hierarquizadas conforme suas características evolutivas, com padrões uniformes de paisagens que guardam singularidades expressas no modelado da superfície terrestre como herança da dinâmica geoambiental oriunda do Quaternário.

O mapeamento foi realizado na escala de trabalho de 1/50.000 a partir da interpretação de imagens orbitais do satélite LANDSAT 8 havendo um apoio consistente de campo. Assim, a compartimentação geoambiental foi representada na escala de 1/220.000, sendo delimitadas no mapa 6 as unidades maiores (geossistemas) e as unidades menores (geofácies), são elas:( Depressão Sertaneja: Depressão Periférica Subúmida Seca e Cristas Residuais e Inselbergs); (Planalto da Ibiapaba: Vertente Úmida, Platô úmido e Reverso Seco) e (Depressão Monoclinal: Depressão Monoclinal Seca). Como expõe os quadros:

Quadro I: Depressão Periférica Subúmida-Seca

Características Naturais e Tipologias de Uso

Superfícies planas moderadamente dissecadas com incisão da drenagem subsequente em padrões dendrídicos e subdendrídicos. Os rios possuem regime intermitente sazonal. O clima assume condições semiáridas, tendendo a subúmidas à medida que se aproxima dos rebordos do planalto. O mosaico de solos assume maior complexidade, prevalecendo os Planossolos, Neossolos Litólicos e os Argissolos Vermelho-Amarelos revestidos por caatingas arbustivas e arbóreas. As tipologias de uso agregam a agricultura de sequeiro associado à pecuária extensiva, Área em pousio, além de Áreas legalmente protegidas nos setores que integram a Área delimitada pelo PARNA de Ubajara.

\section{Problemas Ambientais Configurados}

- Remoção dos horizontes superficiais dos solos por efeito de torrentes

- Desmatamento da caatinga arbórea para rotação de terras no sistema agrícola de sequeiro.

- Ampliação das pastagens e emprego de técnicas agrícolas rudimentares

\section{Diretrizes}

- Manejo agrosilviopastoril adequado e técnicas de conservação dos solos

- Cumprimento da legislação ambiental pertinente às Áreas de Preservação Permanente em torno dos cursos fluviais e monitoramento de bacias hidrográficas;

- Manutenção da caatinga arbórea e controle da pecuária extensiva

Fonte: Adaptado de Souza (2000), elaborado pelos autores.

Quadro II: Cristas Resíduais e Inselbergs

Características Naturais e Tipologias de Uso

Correspondem a setores de maior resistência litológica face ao aplainamento progressivo do relevo regional no contexto da depressão sertaneja. A drenagem possui padrão dendrítico com regime intermitente sazonal encaixada sobre o embasamento cristalino em áreas de elevado declive. Condições climáticas que tendem de subúmidas a semiáridas. Prevalecem os Neossolos Litólicos revestidos pela caatinga arbustiva-arbórea. As tipologias de uso correspondem as Áreas Legalmente Protegidas pertinentes as Áreas de Preservação Permanentes de vertentes íngremes e topos de morros.

Problemas Ambientais Configurados

-Degradação de nascentes fluviais 
- Desmatamento potencializando ações erosivas intensificadas

- Ocorrência de queimadas em descumprimento da legislação ambiental pertinente

\section{Diretrizes}

- Cumprimento da legislação ambiental pertinente ás Áreas de Preservação Permanente

- Incentivo a prática de turismo de aventura como voo livre (parapente) e rapel

- Monitoramento de nascentes fluviais e conservação da caatinga arbórea

Fonte: Adaptado de Souza (2000), elaborado pelos autores.

Quadro III: Vertente Úmida

\section{Características Naturais e Tipologias de Uso}

Relevos dissecados com incidência de festonamentos havendo em diversos setores a exumação do embasamento cristalino em cristas e lombadas. Drenagem obsequente com regime fluvial semiperene confluindo coletores até a Bacia do rio Coreaú. Condições climáticas úmidas e subúmidas com totais pluviométricos anuais de 900 a $1200 \mathrm{~mm}$. Dominam os Argissolos Vermelho-Amarelos com fertilidade natural de média a alta revestidos primariamente pela mata de encosta. As tipologias de uso correspondem as Áreas Legalmente Protegidas pertinentes as Áreas de Preservação Permanentes de vertentes íngremes e topos de morros, além do Parque Nacional de Ubajara.

- Represamento e desvio de cursos fluviais

- Degradação da biodiversidade primária da mata plúvio-nebular

- Movimentos gravitacionais de massa e queda de materiais rochosos

- Monitoramento das nascentes fluviais e incentivo ao percurso de trilhas ecológicas

- Efetivar a delimitação da área do PARNA de Ubajara e monitoramento das nascentes fluviais

--Controle de queimadas com a preservação compulsória dos setores ambientais estratégicos

Fonte: Adaptado de Souza (2000), elaborado pelos autores.

Quadro IV: Platô Úmido

\section{Características Naturais e Tipologias de Uso}

Superfícies de cimeira com altitudes de 750-900m suavemente onduladas, entalhadas por cursos d'água consequentes que dissecam a superfície em interflúvios tabulares. A drenagem possui padrão paralelo com regime fluvial semiperene convergindo para o rio Parnaíba. Canais obsequentes drenam no sentido do rio Coreaú. Condições climáticas úmidas com precipitações anuais que superam $1200 \mathrm{~mm}$. Dominam os Latossolos Vermelho-Amarelos revestidos pela mata plúvio-nebular. As tipologias de uso se diversificam em função das potencialidades ambientais, sendo elas: - Policultura Associada à Pecuária Semi-Intensiva, Área em Pousio, Parque Nacional de Ubajara, Área Urbana e Agricultura Técnificada.

\section{Problemas Ambientais Configurados}

- Perda da biodiversidade com avanço da sucessão ecológica

-Supressão do recobrimento vegetacional primário com poucos remanescentes de mata plúvio-nebular

-Uso indiscriminado de agrotóxicos contaminando os recursos hídricos superficiais e subterrâneos

\section{Diretrizes}

- Uso moderado de agrotóxicos e incentivo a agroecologia através de técnicas de conservação dos solos contribuindo para manutenção dos remanescentes de mata plúvio-nebular;

- Monitoramento da Zona de Amortecimento correspondente a área de influênia do Parque Nacional de Ubajara, estabelecendo as restrições legais pertinentes aos princípios do SNUC;

-Criação de Reservas Particulares do Patrimônio Natural (RPPNs) com incentivo ao ecoturismo

Fonte: Adaptado de Souza (2000), elaborado pelos autores.

Quadro V: Reverso Seco

\section{Características Naturais e Tipologias de Uso}

Superfícies com caimento topográfico suave no sentido oeste entalhada por cursos fluviais consequentes. A drenagem possui paralelo com a elaboração de vales pedimentados. Os rios apresentam regime intermitente sazonal confluindo para o rio Parnaíba. Condições climáticas semiáridas com significativa escassez das precipitações. Dominam os Neossolos Quartzarênicos revestidos pelo "carrasco". As tipologias de uso incluem ás áreas em pousio e vetores de degradação ambiental são: Agricultura técnificada, Agricultura de sequeiro associada à pecuária extensiva.

\section{Problemas Ambientais Configurados}

-Ocupação das ÁPPs em torno dos rios e reservatórios artificiais

- Desmatamento e exposição dos solos aos processos erosivos

-Supressão do carrasco para expansão da pecuária extensiva e agricultura

\section{Diretrizes}

Conservação da biodiversidade do "carrasco" e monitoramento das fronteiras agrícolas;

- Cumprimento da legislação ambiental pertinente às Áreas de Preservação Permanente controlando a pressão exercida pela da 
agricultura tecnificada sobre as planícies fluviais;

- Controle das fronteiras agrícolas na zona de ecótono entre a mata plúvio-nebular e o carrasco com a criação de corredores ecológicos devidamente monitorados com vinculação a atividade ecoturística

$$
\text { Fonte: Adaptado de Souza (2000), elaborado pelos autores. }
$$

Quadro VI: Depressão Monoclinal Seca

\section{Características Naturais e Tipologias de Uso}

Superfície de aplainamento com características que comprovam a ação dos processos exodinâmicos sobre o arcabouço estrutual da sinéclise. Os níveis altimétricos chegam a $300 \mathrm{~m}$ em semelhança a depressão sertaneja. Condições climáticas semiáridas. Os rios possuem padrão paralelo com regime intermitente sazonal, confluindo para o rio Parnaíba. Prevalecem os Neossolos Quartzarênicos revestidos pelo "carrasco". As tipologias de uso são: Agricultura de sequeiro associada à pecuária extensiva e a Área em Pousio

\section{Problemas Ambientais Configurados}

-Desmatamento para ampliação de áreas de pastagens

- Exposição dos solos aos processos erosivos

-Ampliação de áreas degradadas pelo uso agrícola incompatível

\section{Diretrizes}

- Conservação da biodiversidade do "carrasco" e monitoramento das fronteiras agrícolas;

- Controle de queimadas e a adoção de práticas agrícolas conservacionistas

- Criação de áreas destinadas ao patrimônio geológico-gemorfológico, a exemplo das rupturas de declive entre o reverso e a depressão monoclinal de entalhe da drenagem consequente.

Fonte: Adaptado de Souza (2000), elaborado pelos autores.

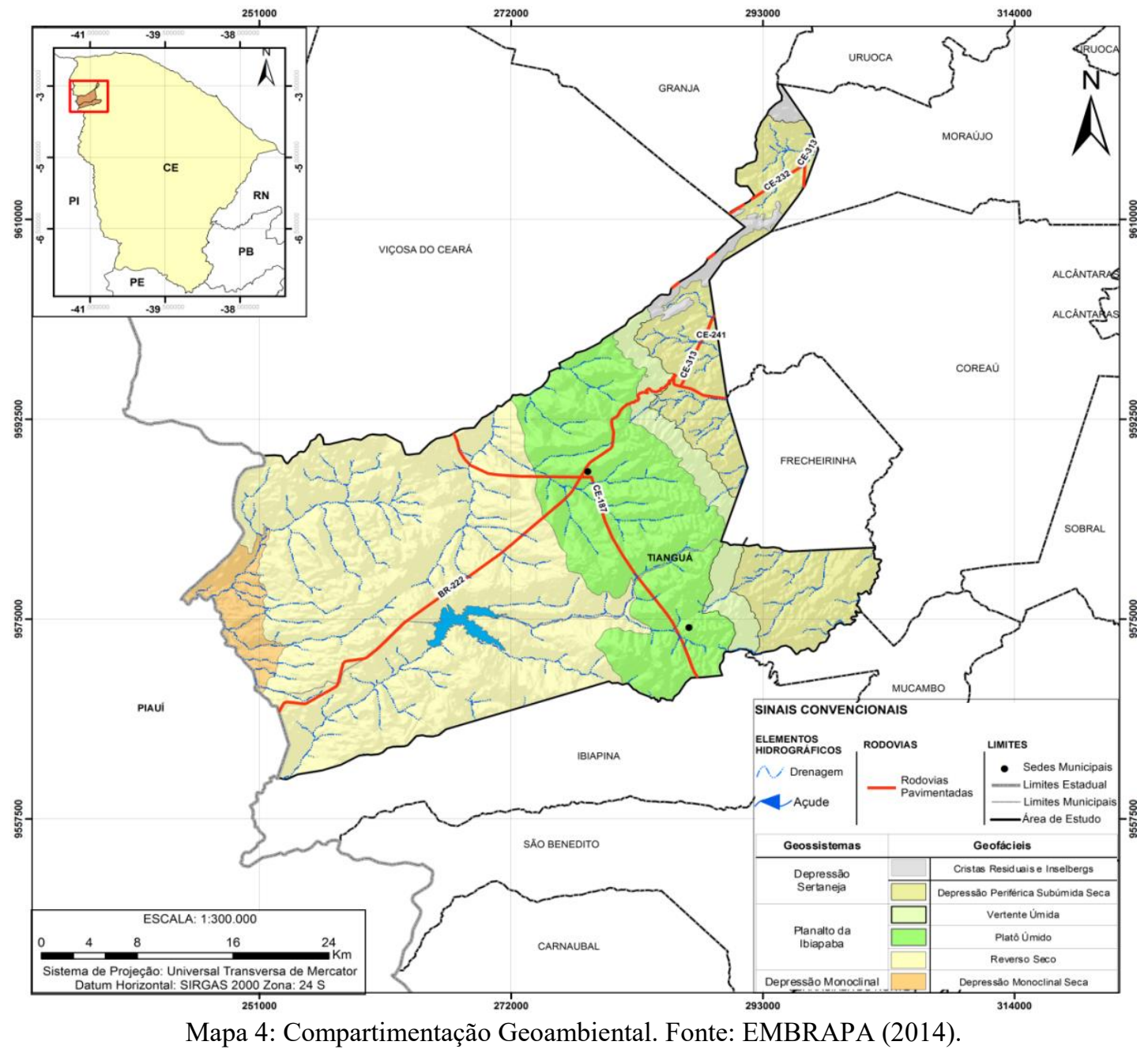




\section{Considerações Finais}

As tipologias de uso e ocupação se materializam no espaço geográfico em virtude da exploração dos recursos naturais na cadeia produtiva. Por consequência, os problemas ambientais apresentaram especificidades em cada sistema de relações interdependentes em razão da intervenção técnica da sociedade sobre o meio físico-biótico. Desta feita, os tensores que desencadeiam a ruptura do equilíbrio da natureza são: ocupação de APPs; uso indiscriminado de agrotóxicos; manejo inadequado da irrigação e expansão das fronteiras do agronegócio sobre a biodiversidade primária.

Assim, a compartimentação geoambiental subsidia o ordenamento territorial dos municípios de Tianguá e Ubajara através da alocação de um padrão de desenvolvimento economicamente viável para sociedade atrelado ao manejo adequado dos recursos naturais em vias sustentáveis.

Diante disso, a proposta de ordenamento territorial, se configura em um desdobramento da metodologia geossistêmica que almeja a materialização do planejamento ambiental no cerne da produção do espaço geográfico. Desta forma, os processos de uso e ocupação são regulamentados por critérios delineados pela compartimentação geoambiental, possibilitando um maior número de acertos para o enfrentamento da sociedade civil com os processos de tomada de decisões públicas.

\section{Bibliografia}

BRASIL. Novo Código Florestal Brasileiro. Lei No 12727/12, Brasília, DF.

AB' SABER, Aziz Nacib. Um conceito de Geomorfologia a serviço das pesquisas sobre o Quaternário. In: Geomorfologia, 18, São Paulo, IGEOG-USP, 1969, p. 1-23.

BERTRAND, G. Paisagem e Geografia Física Global: esboço metodológico. São Paulo: Instituto de Geografia da USP, 1972. (Caderno de Ciências da Terra, 13).

BRASIL. Sistema Nacional de Unidades de Conservação (SNUC). Lei no 9.985 de 18 de julho de 2000.

EMBRAPA. Empresa Brasileira de Pesquisa Agropecuária. Brasil em Relevo: Monitoramento por Satélite. Download da SRTM. Brasília: EMBRAPA, 2014. Disponível em: (http://www.relevobr.cnpm.embrapa.br/). Acesso em 22 de Março de 2014.

IPECE. Instituto de Pesquisa e Estratégia Econômica do Estado do Ceará. Ceará em Mapas: Informações Georrefenciadas e Espacializadas do Estado do Ceará (Meio Ambiente). Fortaleza, 2013. Disponível em http://www.ipece.ce.gov.br. Acesso em 25 de abril de 2013.

NASCIMENTO, F. R. Degradação Ambiental e Desertificação no Nordeste Brasileiro: o contexto da bacia hidrográfica do rio Acaraú - Ceará. Tese (Doutorado em Geografia) - Universidade Federal Fluminense, Niterói, 2006. 325 p.

SOUZA, M. J. N. Bases naturais e esboço de zoneamento geoambiental do estado do Ceará. In: LIMA, L. C., SOUZA, M. J. N., MORAES, J. O. (orgs.). Compartimentação territorial e gestão regional do estado do Ceará. Fortaleza: Editora $\mathrm{F}$

$\mathrm{U}$

$\mathrm{N}$

$\mathrm{E}$

C

E

0 